\title{
A narrative review of malignant eosinophilic pleural effusion: incidence, etiology and prognostic significance
}

\author{
Wen-Jie Li ${ }^{1}$, Zhi-Di Lin ${ }^{1}$, Jin-Lin Wang ${ }^{2,3}$ \\ ${ }^{1}$ Nanshan School, Guangzhou Medical University, Jingxiu Road, Panyu District, Guangzhou, China; ${ }^{2}$ Department of Respiratory, The State Key \\ Laboratory of Respiratory Disease, Guangzhou, China; ${ }^{3}$ Clinical Research Center for Respiratory Disease, Guangzhou Institute of Respiratory \\ Disease, Guangzhou, China \\ Contributions: (I) Conception and design: WJ Li, JL Wang; (II) Administrative support: JL Wang; (III) Provision of study materials or patients: None; \\ (IV) Collection and assembly of data: WJ Li; (V) Data analysis and interpretation: None; (VI) Manuscript writing: All authors; (VII) Final approval of \\ manuscript: All authors. \\ Correspondence to: Prof. Jin-Lin Wang. The First Affiliated Hospital of Guangzhou Medical University, 151 Yan Jiang Xi Road, Guangzhou, China. \\ Email: drjlwang@126.com.
}

\begin{abstract}
Eosinophilic pleural effusion (EPE) is defined as a pleural fluid with an eosinophilic count exceeding $10 \%$ and currently considered to be mainly caused by malignancy. However, the incidence, etiology and prognostic significance of malignant eosinophilic pleural effusion (MEPE) have not been studied extensively yet. Thus, the objective of this review was to summarize medical studies regarding MEPE to 2020 throughout an extensive search of PubMed. Overall, MEPE was a disease associated with multiplecytokines-mediated immunity and varied from $4 \%$ to $92 \%$ of patients who had EPE. The discrepancy of the MEPE prevalence among studies could be explained by the development of diagnostic technology, disparity of study population, or various disease spectrum over time. Data summarized in this review demonstrated that the incidence of malignancy was lower in EPEs than in non-EPEs (29.7\% vs. 32.9\%). Additionally, MEPE could be a manifestation of a great variety of tumor subtypes, among which lung cancer was the most common cause and accounted for more than $34 \%$ of cases. The second common causes were non-Hodgkin lymphoma and metastatic cancers with unknown primary site which were observed in around $5 \%$ of cases, respectively. The presence of eosinophils in the pleural effusion may be associated with a positive prognosis of MEPE. Besides, the prognosis of MEPE may be related to the percentage of eosinophils in the pleural fluid. More extensive studies, however, are warranted to validate these findings.
\end{abstract}

Koywords: Malignant eosinophilic pleural effusion (MEPE); incidence; etiology; prognosis

Submitted Aug 29, 2020. Accepted for publication Dec 31, 2020.

doi: 10.21037/apm-20-1742

View this article at: http://dx.doi.org/10.21037/apm-20-1742

\section{Introduction}

Eosinophilic pleural effusion (EPE), a pleural effusion in which eosinophils account for $\geq 10 \%$ of the white blood cells (WBCs), was described firstly by Harmsen in 1894 (1). Since then, it has been of great interest to clinicians. EPEs account for $5-16 \%$ of exudative pleural effusions and can be a manifestation of an extreme variety of diseases, including infections, malignancies, drug reactions, autoimmune diseases, pulmonary embolism, chest trauma and many others (1). In light of literatures from recent four decades, the most common cause of EPE was malignancy followed by idiopathic and parapneumonic effusions (2). Nonetheless, most information about malignant eosinophilic pleural effusion (MEPE) came from small series and case reports. The incidence, etiology and prognosis of MEPE still remain largely unclear. An understanding of MEPE prevalence and etiology will contribute to the development of novel treatments. Thus, the overarching goal of our work is to summarize current literatures regarding incidence, etiology and prognosis significance of MEPE. We present the 
following article in accordance with the Narrative Review reporting checklist (available at http://dx.doi.org/10.21037/ apm-20-1742).

\section{Methods}

PubMed was used to retrieve for clinical studies including prospective and retrospective studies regarding EPE. The publication date of searched literatures was from the inception of databases to 2020 and there were no restrictions on publication types, regions, or languages. The following MeSH terms and their combinations were used in [Tittle/abstract]: "eosinophilic pleural effusion" OR "malignant pleural effusion" OR "malignant eosinophilic pleural effusion" OR "incidence" OR "etiology" OR "prognostic". We also reviewed the related articles to broaden the scope of search. Studies enrolling adolescents (under 18 years of age) were excluded.

\section{Definition and diagnosis of MEPE}

MEPE is commonly considered as EPE ascribed to malignant etiology. Since malignancies were only observed in exudates, many studies took exudates pleural effusions into considerations and excluded transudates $(1,3,4)$. Certain conditions were well-known to frequently produce EPE, including the bloody effusion, pneumothorax, chest trauma, previous pleural puncture or drug reaction $(1,3)$. MEPE should be diagnosed after exclusion of above risk factors.

Studies involved clinical characteristics of MEPE are scare. Reechaipichitkul et al. (5) demonstrated that patients with malignant pleural effusion (MPE) had a significantly longer duration ( $>1$ month) of clinical symptoms than those with benign EPE, including cough, dyspnea, chest discomfort, hemoptysis, pain, and weight loss. This may be proportional to the volume of pleural effusion (6). However, a quarter of patients were asymptomatic from a respiratory perspective. The pleural fluid profile, abnormal chest radiographs, and blood eosinophilia of MEPE were also not specific (6). Thus, histologic examinations should be required.

In summary, based on the definition of EPE and MPE, MEPE was diagnosed in patients who had:

(I) EPE that is pleural fluid contains at least $10 \%$ of eosinophils among the WBCs in the first thoracentesis;

(II) Exudative pleural fluid/exudates;
(III) A positive pleural fluid cytology and/or positive histology pleural biopsy (proven malignant effusion) (7), or a known malignancy after excluding alternative causes of EPE.

\section{Incidence of MEPE}

According to past publications for decades, the prevalence of MEPE varied from $4 \%$ to $92 \%$ of patients who had EPE (Table 1). The diagnosis of MEPE is affected by various factors.

It was once believed that the finding of pleural fluid eosinophilia in an exudative effusion considerably reduced the probability of malignancy, and increased conversely the likelihood of an underlying benign disorder (13). It was even suggested that malignancy was not a cause of EPEs (13). The studies of Adelman et al. (13) and Kalomenidis et al. (1) reported that air/blood in the pleural space was the most common cause of EPE (29\%). It was also found that a high percentage of idiopathic effusions were characterized by EPE $(11,13)$. Nevertheless, the spectrum of EPEs has changed since 1960, and malignancy should no longer be considered uncommon among EPEs (2). The cumulative incidence of malignancy among EPEs has gradually increased from $7 \%$ to $25 \%$ over the last 4 decades (2). The current studies confirmed that malignancy was the most common etiology related to EPE (ranging from 22.7\% to $40.1 \%)(2,7,13,18,22)$. The tendency may be explained by the development of diagnostic technology, improved diagnostic awareness, disparity of study population, or various disease spectrum over time. Additionally, idiopathic pleural effusions can be defined as non-specific pleuritis which is a diagnosis made after the pleural biopsy and without a definitive aetiology (23). Of note, more than $10 \%$ of these cases could be subsequently found to have malignancy during the follow-up periods (23).

The diagnostic criteria were somehow different from study to study. The diagnosis of malignancy required a pathological confirmation in some literatures but in others the diagnosis was conducted based on clinical findings. The prevalence of MEPE was significantly lower in patient cohorts that involved a pathological confirmation (2). Methods of pathological diagnosis were made up of pleural biopsy, pleural fluid cytology, thoracotomy and autopsy. Furthermore, the prevalence of MEPE was likely underestimated because of insufficient durations of followup for MEPE when an initial work was unrevealed.

Another reason for the difference of MEPE incidence 
Table 1 The incidence of MEPE

\begin{tabular}{|c|c|c|c|c|c|c|c|c|}
\hline Year & First author & Country & Type of study & $\begin{array}{l}\text { Patients } \\
\text { with PE, n }\end{array}$ & $\begin{array}{c}\text { Patients } \\
\text { with EPE, n }\end{array}$ & $\begin{array}{c}\text { Patients with } \\
\text { EPE/all patients } \\
\text { with PE, \% }\end{array}$ & $\begin{array}{c}\text { Patients } \\
\text { with MEPE, n }\end{array}$ & $\begin{array}{l}\text { Patients with } \\
\text { MEPE/patients } \\
\text { with EPE, \% }\end{array}$ \\
\hline 1973 & Light (9) & USA & Pro- & 182 & 8 & 4 & 1 & 13 \\
\hline 1974 & Kokkola (10) & Finland & Retro- & 476 & 78 & 16 & 6 & 8 \\
\hline 1981 & Pettersson (12) & Finland & Pro- & 140 & 26 & 19 & 1 & 4 \\
\hline 1984 & Adelman (13) & USA & Review & NA & 343 & NA & 27 & 8 \\
\hline 1985 & Wysenbeek (14) & Isreal & Retro- & NA & 36 & NA & 7 & 19 \\
\hline 1989 & Kuhn (3) & Switzerland & Pro- & 160 & 19 & 12 & 9 & 47 \\
\hline 1996 & Rubins (17) & USA & Pro- & 476 & 44 & 9.2 & 9 & 21 \\
\hline 2000 & Martínez-García (18) & Spain & Retro- & 358 & 45 & 13 & 11 & 24 \\
\hline 2003 & Matthai (19) & India & Pro- & 444 & 26 & 6 & 4 & 15 \\
\hline 2003 & Reechaipichitkul (5) & Thailand & Retro- & NA & 50 & NA & 46 & 94 \\
\hline 2003 & Kalomenidis (1) & USA & Review & NA & 53 & NA & 15 & 28 \\
\hline 2007 & Ozkara (20) & Turkey & Retro- and Pro- & 697 & 60 & 9 & 22 & 37 \\
\hline 2009 & Krenke (7) & Poland & Retro- & 1,868 & 135 & 7.2 & 47 & 35 \\
\hline
\end{tabular}

Retro-, retrospective; Pro-, prospective; NA, not available; PE, pleural effusion; EPE, eosinophilic pleural effusion; MEPE, malignant eosinophilic pleural effusion.

in different studies may be the discrepancy of the local prevalence of malignancy. Adelman et al. (13) estimated the probability of malignancy in an eosinophilic pleural fluid throughout Bayes' theorem. As a result, the likelihood of malignancy varied from $14 \%$ to $39 \%$. However, the proportions were far below those observed by Kuhn et al. (3) who utilized the same approach and found that the probability of malignancy was $40 \%$ from $47 \%$. Hence, when evaluating the results, the disease spectrum of the study population should be given serious consideration $(5,22)$. Various outcomes of MEPE prevalence were mere reflections of the population investigated.

The confounding factors known to frequently cause EPE is difficult to be excluded. Chung et al. (24) reported that repeated thoracenteses might induce an increase in the number of pleural fluid eosinophils in patients with malignant PE. Conversely, Rubins et al. (17) concluded that repeated thoracenteses within 2 to 12 weeks reduced rather than produced EPE. However, accumulating work indicated that the prevalence of EPEs with a repeated thoracentesis was similar to that of EPEs with the first thoracentesis $(7,18)$. Most studies failed to take it into consideration whether pleural fluid eosinophilia was found on the first or subsequent thoracenteses but others not. In short, this should be taken into account in future work. Moreover, other risk factors including blood or air in the pleural space, drug interaction and other obscure potential conditions (2). Wysenbeek et al. (14) demonstrated that the MEPE percentage decreased from $33 \%$ to $3.8 \%$ after ruling out all additional etiologies for EPE. 
Table 2 The incidence of MEPE in EPE and non-EPE

\begin{tabular}{|c|c|c|c|c|}
\hline First author, year & Total (EPE/non-EPE) & The number of MEPE in EPE (\%) & The number of MEPE in non-EPE (\%) & $P$ value \\
\hline Hirsch, 1979 (11) & $23 / 246$ & $8(34.8)$ & $109(44.3)$ & NS \\
\hline Pettersson, 1981 (12) & $25 / 89$ & $1(4)$ & $23(25.8)$ & S \\
\hline Mihailescu, 1985 (25) & $10 / 126$ & $3(30)$ & $73(57.9)$ & NS \\
\hline Lakhotia, 1989 (15) & $17 / 135$ & $1(5.9)$ & $31(23)$ & NS \\
\hline Rubis,1996 (17) & $44 / 432$ & $10(22.7)$ & $118(27.3)$ & NS \\
\hline Riantawan,1998 (26) & $31 / 363$ & $24(77.4)$ & $135(37.2)$ & S \\
\hline Martínez-García, 2000 (18) & $45 / 313$ & $11(24.4)$ & $84(26.8)$ & NS \\
\hline
\end{tabular}

NS, not significant; S, significant; EPE, eosinophilic pleural effusion; MEPE, malignant eosinophilic pleural effusion.

\section{Incidence of MEPE in EPE and Non-EPE}

The majority of previous studies found that malignancy was as prevalent among eosinophilic as non-EPEs (Table 2). In a prospective cohort enrolling 476 consecutive patients with thoracentesis, malignancy was as frequent among eosinophilic as non-EPEs (20.5\% vs. 20.1\%) (17). Ferreiro et al. (21) illustrated that there were no significant differences in the incidence of neoplasm between the EPE and non-EPE ( $30 \%$ vs. 25.9\%, $\mathrm{P}=0.533$ ). Nevertheless, one more recent meta-analysis (2) of 8 studies suggested that the prevalence of malignancy was lower in EPEs than in nonEPEs (odds ratio: $0.51,95 \%$ confidence interval: 0.32 to $0.78 ; \mathrm{P}=0.001$ ) except in one study (11). In accordance with the results of meta-analysis, this review summarized the latest articles and found that the incidence of malignancy was lower in EPEs than in non-EPEs (29.7\% vs. 32.9\%) (Table 2).

\section{Spectrum of diseases associated with MEPE}

In light of literature review, a vast majority of MEPE was associated with solid tumors and only a small group of patients with hematological malignancies developed EPE (7). The etiology of MEPE is clearly shown in Table 3.

The summary of data demonstrated that lung cancer, especially the non-small-cell lung adenocarcinoma histocyte as well as metastatic cancer to lung $(6,7)$, was the most leading cause of MEPE and accounts for more than
34\% MEPE cases ( $\mathrm{n}=23)$. Non-Hodgkin lymphoma and metastatic carcinomas with unknown primary site were the second most common causes for MEPE accounting for $5 \%$ of patients with MEPE. These results corroborated the previous findings illustrating that the percentage of MEPE with unknown primary site of cancer accounted for $5 \%$ to $10 \%$ (7). Pathological classification mainly included adenocarcinoma, squamous cell carcinoma, dysgerminoma $(5,19)$. Other etiologies (thyroid carcinoma, prostate carcinoma, pancreatic carcinoma, and so forth) were relatively less common.

\section{Pathogenesis}

It is acknowledged that pleural effusion is attributed to the reason that cancer growth obstructs the lymphatic drainage (31). However, the differences in pathogeneses among EPE, MPE and MEPE are largely unknown. According to recent search progress, we propose herein some mechanisms accounting for the development of MEPE.

In general, the EPE formation is divided into two steps: accumulation and migration (32). Accumulation of eosinophils to tissues occurs in consequence of boosted eosinophil production in the bone marrow. Migration is followed by firm cytoadherence between eosinophils and endothelial cells. It should be addressed that the power of tumor-host cell interactions may become pronounced with the MEPE development (33). Eosinophils were known for 
Table 3 The etiology of MEPE

\begin{tabular}{|c|c|c|}
\hline Carcinoma types & The number of reported cases in the references (\%) & References \\
\hline Pleural malignancy & $2(3.0)$ & $(19,20)$ \\
\hline Unknown primary site (metastatic carcinoma) & $5(7.5)$ & $(7,20)$ \\
\hline Breast carcinoma & $3(4.5)$ & $(7)$ \\
\hline Malignant mesothelioma & $2(3.0)$ & (7) \\
\hline Hodgkin lymphoma & $2(3.0)$ & $(7,20)$ \\
\hline Non-Hodgkin lymphoma & $5(7.5)$ & $(7,20,27,28)$ \\
\hline Malignant lymphoma & $2(3.0)$ & $(29,30)$ \\
\hline Prostate carcinoma & $1(1.5)$ & (7) \\
\hline Urethelial carcinoma & $1(1.5)$ & (7) \\
\hline Multiple myeloma & $2(3.0)$ & $(7,30)$ \\
\hline Chronic myeloid leukaemia & $1(1.5)$ & $(7)$ \\
\hline Malignant melanoma & $1(1.5)$ & (7) \\
\hline Malignant fibrohistiocytoma & $1(1.5)$ & (7) \\
\hline Ampulla of Vater carcinoma & $1(1.5)$ & (7) \\
\hline Cholangiocarcinoma & $1(1.5)$ & (7) \\
\hline Papilla Vateri carcinoma & $1(1.5)$ & (20) \\
\hline Colon carcinoma & $1(1.5)$ & (20) \\
\hline Urinary bladder carcinoma & $1(1.5)$ & (20) \\
\hline Testicular seminoma & $1(1.5)$ & (20) \\
\hline
\end{tabular}

allergies and parasites infections (34). However, many tumor cells were found to release chemokines that could recruit adhesion molecules and eosinophils (34). Hu et al. (35) found that the level of interleukin (IL)-33, acting as chemoattractant of eosinophils and other potent chemokines including IL-4 and IL-5 (35,36), was significantly higher in patients with non-small-cell lung cancer than those with benign lung diseases. Tumor necrosis factor (TNF)- alpha produced by tumor cells was also reported to regulate pleural microenvironment in the development of MPE and drastically stimulate eosinophils (37). Moreover, Ali et al. (38) expounded that breast carcinoma cell expressed vascular cell adhesion molecule-1 (VCAM-1), which could enhance adherence of eosinophils to endothelial cells.

Increasing work demonstrated that eosinophils were not bystander cells in tumorigenesis due to pleiotropic 
effects. Eosinophils were able to secrete a range of anticancer molecules, including lipid mediators, cytotoxic granules, cytokines, growth factors and chemokines (34). These factors were shown to be cytotoxic in human cancer cell lines both in vivo and vitro. For example, eosinophil cytotoxic granules were shown to serve as a chemoattractant for T cells, neutrophils as well as dendritic cells and possess strong cytotoxic activity against human tumor cell lines $(39,40)$. Tumor-homing eosinophils could also excrete a range of cytokines (such as, TNF- $\alpha$, IL-4, and IL-5) which were associated with $\mathrm{T}$ cells (40) and chemokines which attracted $\mathrm{T}$ cells to the carcinoma microenvironment, leading to tumor eradication (41). Besides, eosinophils enhanced dendritic cell maturation throughout the increased expression of cell surface activation markers (42). Dendritic cells potentially overcame tumor tolerance and were related to good prognosis in carcinoma patients (43). Eosinophils were also able to serve as antigen presenting cells, migrate to local lymph nodes with antigen, and subsequently stimulate the expansion of $\mathrm{T}$ lymphocytes (44). Of note, eosinophils had the tumoricidal effects of various cancer cells throughout stable close contacts with target cells, expressing the same receptors and mediators as cytotoxic T lymphocytes (45).

\section{Treatment and management of MEPE}

Unfortunately, most existing MEPE management strategies fail to result in prolonged survival, and the primary purpose of management of patients with MEPE is to control symptoms and prevent recurrence of pleural effusions (46). Systemic radiotherapy, chemotherapy, or hormone therapy are available to control the MPE, particularly in small cell lung cancer (46). Strategies including chest-tube thoracostomy, needle drainage with thoracentesis, indwelling pleural catheter, or thoracoscopy with pleurodesis may alleviate patient symptoms $(47,48)$. Achieving pleurodesis may impart a survival benefit in patients (48). Additionally, it has been reported that patients treated with pleurodesis at video-assisted thoracoscopy may have longer survival (49).

\section{Prognostic significance of MEPE}

As stated above, eosinophils may be established as prognostic markers given their role in cancer progression. They have been shown to be associated with a beneficial prognosis in most cases. For example, high eosinophilic infiltration of the colorectal cancer was associated with a beneficial 5-year overall survival rate (50). A reduced risk of tumor recurrence was present in breast cancer cases with a high peripheral eosinophil count (51). Furthermore, a previous study illustrated a correlation between an increased overall survival as well as disease-free survival and the intensity of tumor-associated tissue eosinophilia (52). Especially, overall survival would increase in intratumoral tumor-associated tissue eosinophilia when compared with other sites (53). In addition, a prospective cohort study found that patients with EPEs had a significantly better survival than those with non-EPEs (a median survival of 16.8 months compared with 7.7 months) (17). To date no evidence has revealed the difference of survival between MEPE and MPE. Evidence showed that survival of MPE may be depended on tumor subtypes, range from 50 days to almost a year (54). We assumed that eosinophils may contribute to a more favourable prognosis for MEPE based on current publications, and further studies in this regard are warranted to verify this assumption.

The association between eosinophil counts and survival was also assessed in carcinoma entities. High levels of eosinophils resulted in an improved survival rate in gastric carcinoma (55) and hepatobiliary cancer (56). Moreover, the possibility of malignancy was inversely related to the pleural eosinophil counts (2). The likelihood of malignancy was only $7 \%$ when an eosinophil count was more than $32 \%$ (2). Similarly, Chu et al. (22) found that eosinophil count in pleural effusion was a speculative negative predictor for malignancy in patients with EPE when eosinophils exceeded $15 \%$. The analysis of Krenke et al. (7) revealed that an eosinophil percentage of $40 \%$ was the most accurate cut-off level to differentiate between malignant and nonmalignant EPE, which supported the study by Kuhn et al. (3) who suggested that eosinophils exceeded $50 \%$ in the pleural fluid possessed the strongest negative predictability towards malignancy. Furthermore, a high eosinophil count at baseline was potentially associated with an improved overall survival in participants treated with immune checkpoint inhibitors (57).

\section{Conclusions}

Malignancy is the most common etiology related to EPE. Of note, the incidence of MEPE is affected by many variables, including the population investigated, diagnostic criteria or other risk factors of EPE. Unfortunately, most therapy strategies for MEPE to date are unavailable to 
prolong survival. The presence of eosinophil in the pleural effusion may denote a positive prognosis of MEPE. The percentage of eosinophils may be an interesting predictor of MEPE prognosis which needs further researches.

\section{Acknowledgments}

All authors appreciate Zhang Tao for the helpful language polishing on this paper.

Funding: None.

\section{Footnote}

Reporting Checklist: The authors have completed the Narrative Review reporting checklist. Available at http:// dx.doi.org/10.21037/apm-20-1742

Peer Review File: Available at http://dx.doi.org/10.21037/ apm-20-1742

Conflicts of Interest: All authors have completed the ICMJE uniform disclosure form (available at http://dx.doi. org/10.21037/apm-20-1742). The authors have no conflicts of interest to declare.

Ethical Statement: The authors are accountable for all aspects of the work in ensuring that questions related to the accuracy or integrity of any part of the work are appropriately investigated and resolved.

Open Access Statement: This is an Open Access article distributed in accordance with the Creative Commons Attribution-NonCommercial-NoDerivs 4.0 International License (CC BY-NC-ND 4.0), which permits the noncommercial replication and distribution of the article with the strict proviso that no changes or edits are made and the original work is properly cited (including links to both the formal publication through the relevant DOI and the license). See: https://creativecommons.org/licenses/by-nc-nd/4.0/.

\section{References}

1. Kalomenidis I, Light RW. Eosinophilic pleural effusions. Curr Opin Pulm Med 2003;9:254-60.

2. Oba Y, Abu-Salah T. The prevalence and diagnostic significance of eosinophilic pleural effusions: a meta-analysis and systematic review. Respiration 2012;83:198-208.
3. Kuhn M, Fitting JW, Leuenberger P. Probability of malignancy in pleural fluid eosinophilia. Chest 1989;96:992-4.

4. Light RW, Macgregor MI, Luchsinger PC, et al. Pleural effusions: the diagnostic separation of transudates and exudates. Ann Intern Med 1972;77:507-13.

5. Reechaipichitkul W, Chuesakoolvanich K. Eosinophilic pleural effusion in adults at Srinagarind Hospital. Southeast Asian J Trop Med Public Health 2003;34:374-8.

6. Tassi GF, Cardillo G, Marchetti GP, et al. Diagnostic and therapeutical management of malignant pleural effusion. Ann Oncol 2006;17 Suppl 2:ii11-2.

7. Krenke R, Nasilowski J, Korczynski P, et al. Incidence and aetiology of eosinophilic pleural effusion. Eur Respir J 2009;34:1111-7.

8. Bower G. Eosinophilic pleural effusion. A condition with multiple causes. Am Rev Respir Dis 1967;95:746-51.

9. Light RW, Erozan YS, Ball WC, Jr. Cells in pleural fluid. Their value in differential diagnosis. Arch Intern Med 1973;132:854-60.

10. Kokkola K, Valta R. Aetiology and findings in eosinophilic pleural effusion. Scand J Respir Dis Suppl 1974;89:159-65.

11. Hirsch A, Ruffie P, Nebut M, et al. Pleural effusion: laboratory tests in 300 cases. Thorax 1979;34:106-12.

12. Pettersson T, Riska H. Diagnostic value of total and differential leukocyte counts in pleural effusions. Acta Med Scand 1981;210:129-35.

13. Adelman M, Albelda SM, Gottlieb J, et al. Diagnostic utility of pleural fluid eosinophilia. Am J Med 1984;77:915-20.

14. Wysenbeek AJ, Lahav M, Aelion JA, et al. Eosinophilic pleural effusion: a review of 36 cases. Respiration 1985;48:73-6.

15. Lakhotia M, Mehta SR, Mathur D, et al. Diagnostic significance of pleural fluid eosinophilia during initial thoracocentesis. Indian J Chest Dis Allied Sci 1989;31:259-64.

16. Kamel A, Chabbou A, el Gharbi B. Eosinophilic pleural effusion. Rev Pneumol Clin 1989;45:118-22.

17. Rubins JB, Rubins HB. Etiology and prognostic significance of eosinophilic pleural effusions. A prospective study. Chest 1996;110:1271-4.

18. Martínez-García MA, Cases-Viedma E, CorderoRodriguez PJ, et al. Diagnostic utility of eosinophils in the pleural fluid. Eur Respir J 2000;15:166-9.

19. Matthai SM, Kini U. Diagnostic value of eosinophils in pleural effusion: a prospective study of 26 cases. Diagn Cytopathol 2003;28:96-9. 
20. Ozkara SK, Turan G, Basyigit I. Clinicopathologic significance of eosinophilic pleural effusions in a population with a high prevalence of tuberculosis and cancer. Acta Cytol 2007;51:773-81.

21. Ferreiro L, San Jose E, Gonzalez-Barcala FJ, et al. Eosinophilic pleural effusion: incidence, etiology and prognostic significance. Arch Bronconeumol 2011;47:504-9.

22. Chu FY, Liou CB, Sun JT, et al. Eosinophilia in Pleural Effusions: a Speculative Negative Predictor for Malignancy. Asian Pac J Cancer Prev 2016;17:1411-4.

23. Wrightson JM, Davies HE. Outcome of patients with nonspecific pleuritis at thoracoscopy. Curr Opin Pulm Med 2011;17:242-6.

24. Chung CL, Chen YC, Chang SC. Effect of repeated thoracenteses on fluid characteristics, cytokines, and fibrinolytic activity in malignant pleural effusion. Chest 2003;123:1188-95.

25. Mihailescu E, Micu D. Eosinophilia in the pleural and peritoneal effusions. Med Interne 1985;23:191-4.

26. Riantawan P, Bangpattanasiri K, Chaowalit $\mathrm{P}$, et al. Etiology and clinical implications of eosinophilic pleural effusions. Southeast Asian J Trop Med Public Health 1998;29:655-9.

27. Chang CJ, Cheng JH, Lin MS, et al. Eosinophilic pleural effusion as the first presentation of angioimmunoblastic $\mathrm{T}$ cell lymphoma. J Formos Med Assoc 2007;106:156-60.

28. Ishida M, Yoshida K, Kagotani A, et al. Anaplastic lymphoma kinase-positive large B-cell lymphoma: a case report with emphasis on the cytological features of the pleural effusion. Int J Clin Exp Pathol 2013;6:2631-5.

29. Henderson AH, Mejia G. Malignant lymphoma presenting with a high eosinophilia, eosinophilic pleurisy, and pericrditis. Thorax 1969;24:124-5.

30. Lipworth BJ, Dhillon DP. A case of eosinophilic pleural effusion complicating multiple myeloma. Scott Med J 1988;33:278.

31. Psallidas I, Kalomenidis I, Porcel JM, et al. Malignant pleural effusion: from bench to bedside. Eur Respir Rev 2016;25:189-98.

32. Kalomenidis I, Light RW. Pathogenesis of the eosinophilic pleural effusions. Curr Opin Pulm Med 2004;10:289-93.

33. Skok K, Hladnik G, Grm A, et al. Malignant Pleural Effusion and Its Current Management: A Review. Medicina (Kaunas) 2019;55:490.

34. Sakkal S, Miller S, Apostolopoulos V, et al. Eosinophils in Cancer: Favourable or Unfavourable? Curr Med Chem 2016;23:650-66.
35. Hu LA, Fu Y, Zhang DN, et al. Serum IL-33 as a diagnostic and prognostic marker in non- small cell lung cancer. Asian Pac J Cancer Prev 2013;14:2563-6.

36. Kwon BI, Hong S, Shin K, et al. Innate type 2 immunity is associated with eosinophilic pleural effusion in primary spontaneous pneumothorax. Am J Respir Crit Care Med 2013;188:577-85.

37. Stathopoulos GT, Kollintza A, Moschos C, et al. Tumor necrosis factor-alpha promotes malignant pleural effusion. Cancer Res 2007;67:9825-34.

38. Ali S, Kaur J, Patel KD. Intercellular cell adhesion molecule-1, vascular cell adhesion molecule-1, and regulated on activation normal $\mathrm{T}$ cell expressed and secreted are expressed by human breast carcinoma cells and support eosinophil adhesion and activation. Am J Pathol 2000;157:313-21.

39. Kubo H, Loegering D, Adolphson C, et al. Cytotoxic properties of eosinophil granule major basic protein for tumor cells. Int Arch Allergy Immunol 1999;118:426-8.

40. Hogan SP, Rosenberg H, Moqbel R, et al. Eosinophils: biological properties and role in health and disease. Clin Exp Allergy 2008;38:709-50.

41. Carretero R, Sektioglu IM, Garbi N, et al. Eosinophils orchestrate cancer rejection by normalizing tumor vessels and enhancing infiltration of CD8(+) T cells. Nat Immunol 2015;16:609-17.

42. Lotfi R, Lotze M. Eosinophils induce DC maturation, regulating immunity. J Leukoc Biol 2008;83:456-60.

43. Sheng KC, Pietersz G, Wright M, et al. Dendritic cells: activation and maturation--applications for cancer immunotherapy. Curr Med Chem 2005;12:1783-800.

44. Xie ZF, Shi H, Qin X, et al. Effects of antigen presentation of eosinophils on lung Th1/Th2 imbalance. Chin Med J (Engl) 2005;118:6-11.

45. Legrand F, Driss V, Delbeke M, et al. Human eosinophils exert TNF- $\alpha$ and granzyme A-mediated tumoricidal activity toward colon carcinoma cells. J Immunol 2010;185:7443-51.

46. Asciak R, Rahman NM. Malignant Pleural Effusion: From Diagnostics to Therapeutics. Clin Chest Med 2018;39:181-93.

47. Penz E, Watt KN, Hergott CA, et al. Management of malignant pleural effusion: challenges and solutions. Cancer Manag Res 2017;9:229-41.

48. Hassan M, Mercer RM, Maskell NA, et al. Survival in patients with malignant pleural effusion undergoing talc pleurodesis. Lung Cancer 2019;137:14-8.

49. Rena O, Boldorini R, Papalia E, et al. Persistent lung 
expansion after pleural talc poudrage in non-surgically resected malignant pleural mesothelioma. Ann Thorac Surg 2015;99:1177-83.

50. Xie F, Liu L, Shang W, et al. The infiltration and functional regulation of eosinophils induced by TSLP promote the proliferation of cervical cancer cell. Cancer Lett 2015;364:106-17.

51. Ownby HE, Roi L, Isenberg R, et al. Peripheral lymphocyte and eosinophil counts as indicators of prognosis in primary breast cancer. Cancer 1983;52:126-30.

52. Dorta RG, Landman G, Kowalski L, et al. Tumourassociated tissue eosinophilia as a prognostic factor in oral squamous cell carcinomas. Histopathology 2002;41:152-7.

53. Jain D, Tikku G, Bhadana P, et al. The Impact of Peritumoral Retraction Clefting \& Intratumoral Eosinophils on Overall Survival in Oral Squamous

Cite this article as: $\mathrm{Li}$ WJ, Lin ZD, Wang JL. A narrative review of malignant eosinophilic pleural effusion: incidence, etiology and prognostic significance. Ann Palliat Med 2021;10(2):2314-2322. doi: 10.21037/apm-20-1742
Carcinoma Patients. Pathol Oncol Res 2019;25:183-9.

54. Clive AO, Kahan BC, Hooper CE, et al. Predicting survival in malignant pleural effusion: development and validation of the LENT prognostic score. Thorax 2014;69:1098-104.

55. Cuschieri A, Talbot I, Weeden S. Influence of pathological tumour variables on long-term survival in resectable gastric cancer. Br J Cancer 2002;86:674-9.

56. Steel JL, Kim K, Dew M, et al. Cancer-related symptom clusters, eosinophils, and survival in hepatobiliary cancer: an exploratory study. J Pain Symptom Manage 2010;39:859-71.

57. Weide B, Martens A, Hassel J, et al. Baseline Biomarkers for Outcome of Melanoma Patients Treated with Pembrolizumab. Clin Cancer Res 2016;22:5487-96. 